\title{
Investigating the Health Related Quality of Life of Zambian Children Living with HIV/AIDS on Antiretroviral Therapy
}

Mukosha Bona Chitah $^{1 *}$, Dick Jonsson ${ }^{2}$ and Venkatesh Seshamani ${ }^{1}$

${ }^{1}$ Department of Economics, University of Zambia, Zambia

${ }^{2}$ Department of Medical and Health Sciences, Linköping University, Sweden

\begin{abstract}
Background: This study deals with Health Related Quality of Life (HRQoL) of children living with HIVIAIDS in Zambia. The study was undertaken in Zambia as a sub-component of the randomised clinical trials for paediatric antiretroviral regimen, designed to test the efficacy of the drug. The purpose of the study was to determine the extent of change in well-being of children with HIVIAIDS resulting from the administration of the FDC drug as well as the acceptance and tolerance of the medication of the drug.

Method: For purpose of $\mathrm{HRQoL}$ measurement, all the relevant data were collected at the following end points after randomization: (1) Pre-trial; (2) Follow up; and (3) End line of the trials. A sample of 211 children were selected. The ARV administration was monitored on a continuous basis through clinic visits and home visits by both the guardians and clinicians.

The PEDsQL TM Questionnaire was used in this study. Based on this, ordered Probit regression models using time and staging of HIV/ AIDS respectively as dependent variables were used for the analysis.

Results: The severity of ill-health (measured by low CD4 counts) impacts upon HRQoL the most. The administration of the specially formulated paediatric ARVs to children with HIVIAIDS brings about an improvement in HRQoL of the children. The improvement in the quality of life is relatively high allowing these children to perform physical, psycho-social and cognitive functions and roles with minimal differences with the performance of these functions by children that are HIVIAIDS negative.

Conclusion: These findings mean that since improving the welfare and well-being of children living with HIVIAIDS can contribute significantly to social and economic welfare, the Government should continue not only to provide ARVs, but ensure universal access to ARVs by children living with HIVIAIDS.
\end{abstract}

Keywords: Health related quality of life; CD4; ARV; Probit regression

\section{Introduction}

This study assesses the Health Related Quality of Life (HRQoL) of Children living with HIV/AIDS in Zambia. According to Fairclough and Diane [1], HRQoL refers to a person's expected social, physical and emotional well-being and how medical conditions or treatment affects any of these individually or collectively. Others, such as Patrick and Erickson [2], adopt a broader approach in which HRQoL is understood to mean the value assigned to duration of life as modified by the impairments, functional states, perceptions and social opportunities that are influenced by disease, injury, treatment or policy.

This HRQoL study was undertaken in Zambia as a sub-component to the randomised Phase III clinical trials for paediatric antiretroviral regimen. The study, called the 'Children with HIV in AfricaPharmacokinetics and Adherence of Simple Antiretroviral Regimens (CHAPAS I Trial', Chapas Protocol (July 2006) was the first of its kind being done using generic formulations of ARVs. Following the clinical trials, case management of HIV/AIDS has since seen some changes. Paediatric treatment guidelines for HIV and AIDS now recommend expanded early access to and initiation of antiretroviral drugs in children in low resource settings. It is now recommended that initiation can be made given "CD4 threshold of 500 cells $/ \mathrm{mm}^{3}$ or less. Priority should, however, be given to individuals and those with CD4 count of 350 cells $/ \mathrm{mm}^{3}$ or less." (p 25 WHO Consolidated Guidelines on the Use of Antiretroviral Drugs for Treating and Preventing HIV Infection: A Public Health Approach). These recommendations are a product of, among other things, clinical trials conducted earlier to make available and ensure access of children to paediatric formulation of ARVs. Children had previously been given adult formulated ARV based on what was available at the time. The drug available at the time was triomune which would be broken for purposes of paediatric administration. A new fixed dose combination [3-5] (FDC) drug, pedimune, was developed combining nevirapine, stavudine and lamivudine, for paediatrics. The clinical trials were designed to test the efficacy of the drug. The purpose of these trials, in terms of HRQoL, was to among other things,

- Describe the toxicity (e.g., rash, hepatic toxicity) that may be related to NVP when NVP is initiated at full dose versus half dose, in order to determine the necessity for dose escalation in African HIVinfected children using fixed dose combinations (FDCs);

- Describe changes in mortality, disease progression, hospital admission rates and laboratory markers (CD4 present, haemoglobin, viral load as measured by plasma HIV RNA) before and after ART.

The above elements represent a change in individual status and well-being that is a function of the CD4 count. Specifically, the purpose of the HRQoL study is to determine the extent of change in well-being as well as the acceptance or tolerance of the medication of the drug, for instance in terms of palatability and other related characteristics by the children. In addition if there are these effects, the study seeks to determine how significant these are in terms of affecting the daily existence of the patients.

HRQoL analysis serves several functions. In this study, we focus on one key function. It is the changes or lack of changes in HRQoL that

*Corresponding author: Mukosha Bona Chitah, Department of Economics, University of Zambia, Zambia, Tel: +260 2112904 75; E-mail: Bona.chitah@unza.zm

Received August 04, 2016; Accepted August 12, 2016; Published August 19, 2016

Citation: Chitah MB, Jonsson D, Seshamani V (2016) Investigating the Health Related Quality of Life of Zambian Children Living with HIVIAIDS on Antiretroviral Therapy. Health Econ Outcome Res Open Access 2: 120. doi: 10.4172/2471$268 x / 1000120$

Copyright: (c) 2016 Chitah MB, et al. This is an open-access article distributed under the terms of the Creative Commons Attribution License, which permits unrestricted use, distribution, and reproduction in any medium, provided the original author and source are credited. 
forms the grounds for rejection, adoption or continued consideration of a treatment intervention. Survival is a logical outcome of a relatively successful treatment or medication. The HRQoL approach considers disease progression and survival outcomes as they are captured in a clinical trial.

\section{Materials and Methods}

\section{Study design, participants and sampling}

The data collection was made at the following points (1) Pretrial commencement (2) Follow up or what may be considered as baseline and midline or and (3) End line of the trials. The pre-trial data comprised the following data:

Blood samples for HIV antibody testing, full blood test (FBT) and a filter paper sample of all children whose parent(s)/carer consented for the child to have an HIV test. All children showing HIV antibody positive had CD4 cell counts taken.

Data obtained following randomisation, included:

1. Clinical data, including weight, height, head circumference, previous hospital admissions, and clinical signs of HIV infection (see Form 2).

2. Resistance testing using a throat swab sample to Streptococcus pneumoniae.

3. Demographic data, including place of residence, number of children in the household, and level of mother and father's education. At discharge, a study nurse will accompany the child to his/her home to establish the place of residence.

Follow up was conducted through clinic and home visits. During these visits clinical examinations for bacterial infections, malaria parasites and full blood count were obtained. During the home visits in particular, the patients state of health was assessed as were adherence and storage of medications. Children also received vitamin A supplementation as appropriate.

The safety of the antibiotic regimen was an important concern of the study. Adverse reactions wherever possible were recorded and the parents or guardian were informed if it was suspected that the trial medication was having adverse reactions on the subject especially in cases of skin rash. Guidelines for the management of adverse reactions were developed and made available for the clinical trials team. Consequently, a recording of any serious adverse events (such as hypersensitivity reactions or hepatitis) possibly attributable to the trial drugs was done.

\section{Inclusion and exclusion criteria}

The paediatric subjects for the study were chosen on the basis of inclusion and exclusion criteria.

The inclusion criteria were the following:

1. They were between 6 months to 14 years inclusive;

2. The parents or guardians as well as children where appropriate, gave informed consent

3. The children were HIV-positive, as determined by positive antibody test in children aged more than 18 months or positive proviral DNA in children less than 18 months.

4. The children were previously untreated with antiretroviral, including any ART given to prevent mother to child transmission, and they further fulfilled the following conditions:

- They met one of the WHO criteria for initiating treatment which included either of:

- $\mathrm{CD} 4<15 \%$ if $>18$ months of age, or $<20 \%$ if $<18$ months of age.

- WHO paediatric stage 4 or severe stage 3 disease, regardless of CD4 $\%$;

- WHO paediatric stage 2 disease with consideration of CD4 \% $(<15$ for children $>18$ months, $<20$ for children $<18$ months).

The exclusion criteria were the following:

1. Children who were unwilling or could not regularly attend the CHAPAS trial centre;

2. Children who faced severe laboratory abnormalities (contraindicate NVP based regimen), i.e., serum creatinine $>5$ times upper limit of normal (ULN) or aspartate aminotransferase (AST) or ALT $>10$ times ULN;

3. If they had active opportunistic infection and/or serious bacterial infection at the time of study entry including TB (children may be enrolled after the acute phase);

4. If they had current treatment with any medication known to be contra-indicated with any of the drugs prescribed for the patient's ART-therapy in this trial, including rifampicin.

211 children were enrolled in a 1:1 ratio to start with Pedimune at either full dose on a twice daily schedule or on a dose escalation schedule of once a day administration for 14 days which is subsequently scaled up to full dose, with the latter schedule having a 50 per cent of normal dose of NVP. Enrolment took place over a 12 month period and followup continued until the last randomised child had completed a 48 week schedule.

\section{Methods and study instruments}

The instrument used in the study was the Paediatric Quality of Life Inventory ${ }^{\mathrm{TM}}$ (PedsQL $\left.{ }^{\mathrm{TM}}\right)$. This instrument is designed to cover the following set of scales:

- Physical functioning,

- Emotional functioning,

- Social functioning, and,

- School (cognitive) functioning.

The instrument has been tested for validity, feasibility and reliability $[6,7]$. The PedsQL ${ }^{\mathrm{TM}}$ is a modular oriented tool designed for assessment of HRQoL in both chronic and acute conditions (http://www.pedsql/ org/about_pedsql.html). It integrates both generic core scales and disease specific modules as a unified measurement tool.

The PedsQL ${ }^{\mathrm{TM}}$ used in the study comprises 23 items of Generic Core Scales designed to measure the core dimensions of health and role (schooling) function. There are four multidimensional Scales and three Summary Scales. Based on this, the following Repeated Measures Model (that is, a model in which time is regarded as a categorical variable and not as a continuous variable as in a Growth Curve Model) was adopted for the regression analysis. The Repeated Measures Model makes reference to specific time periods when data collection occurs.

Repeated Measures Model assumptions: 
m=group type

$\mathrm{i}=$ individual in study

$j=$ assessment of $i t h$ subject in study

From the above, the model is developed as:

$\mathrm{Y}_{\text {mij }}$ corresponds to the $j$ th observation of HRQoL on the $i$ th individual in the $m$ th group. When there does not exist a need for group distinction the indicator, $\mathrm{m}$ can be dropped.

A general linear model for the HRQoL outcomes which is applied to the Repeated Measures Model can then be expressed as:

$$
Y_{i j}=X_{i j} \beta+\varepsilon_{i j}
$$

Where,

$\mathrm{Y}_{\mathrm{i}}=$ the complete data vector of $\mathrm{n}$ planned observations of the outcome for the ith individual, which includes both the observed data and missing data i.e., $\mathrm{Y}_{\mathrm{i}}^{\text {obs }}$ and $\mathrm{Y}_{\mathrm{i}}^{\text {mis }}$.

$\mathrm{X}_{\mathrm{i}}=$ the design matrix of fixed covariates corresponding to the complete data $\left(\mathrm{Y}_{\mathrm{i}}\right)$.

\section{$\beta=$ the corresponding vector of fixed-effects parameters \\ $\varepsilon_{\mathrm{i}}=$ the vector of residual errors}

\section{Background data of the cohort}

In Tables 1 and 2 the salient characteristics of the children are given. Table 1 shows the share of children by the relationship to their guardian. Table 2 shows the demographic and socio-economic structure of the respondents. For instance, the table shows frequency of facility visits, mean expenditures on key items by household's among others. The mean age was 10 years while the range was between 4.1 and 14.9 years. The mean visit to the health centre is 1 and the range lies between 0 and 8 , reflecting the tendency of the trial to provide specialised nursing and physician visits to the children on a fixed basis and for the children to report to the clinical trials clinic on a regular basis. The clinic visits were outside of these scheduled visits, when they were undertaken.

$65 \%$ of the respondents were living with their biological mothers, by far the largest number. The next significant guardians were the aunt and maternal grandmother, who between them accounted for $18 \%$ with all others balanced out with the remaining $16 \%$. Interestingly fathers only accounted for an estimated $4.7 \%$. Following on that, an estimated $85 \%$ of the children continued to be cared for by the person given as the guardian (Table 1 and 2).

\section{Data Analysis and Results}

Based on the interviews, the analytical results are shown below. As can be seen from Table 3, the mean score for the scales range rather highly between 88 and 98 for the physical, emotional, social, school, psycho-social and total scores. The minimum scores start at 30 for school functioning followed by 34 for physical functioning. These results compare with a similar study undertaken by the Paediatric AIDS Clinical Trials Group Protocol 219 Study Team [8] as shown in Table 4.

Cronbach's a was used as a measure of internal reliability. The $\alpha$ results are given in Table 5 and show an acceptably good level of reliability.

In here, one other important result is that there are no discernable

\begin{tabular}{|c|c|c|c|}
\hline Relation & Frequency & Percent & $\begin{array}{c}\text { Cumulative } \\
\text { frequency }\end{array}$ \\
\hline Mother & 361 & 65.28 & 65.28 \\
\hline Father & 26 & 4.7 & 69.98 \\
\hline Brother & 16 & 2.89 & 72.88 \\
\hline Sister & 17 & 3.07 & 75.95 \\
\hline Aunt & 58 & 10.49 & 86.44 \\
\hline Uncle & 10 & 1.81 & 88.25 \\
\hline Cousin & 11 & 1.99 & 90.24 \\
\hline Maternal grandmother & 42 & 7.59 & 97.83 \\
\hline Paternal grandmother & 6 & 1.08 & 98.92 \\
\hline Maternal grandfather & 2 & 0.36 & 99.28 \\
\hline Paternal grandfather & 1 & 0.18 & 99.46 \\
\hline other & 3 & 0.54 & 100 \\
\hline Total & 553 & 100 & \\
\hline
\end{tabular}

Source: Authors' estimates from CHAPAS data set

Table 1: Primary guardian of the child.

\begin{tabular}{|c|c|c|c|c|}
\hline Variable & $\begin{array}{c}\text { Observations (repeated } \\
\text { measurements) }\end{array}$ & Mean age & $\begin{array}{c}\text { Minimum } \\
\text { age }\end{array}$ & $\begin{array}{c}\text { Maximum } \\
\text { age }\end{array}$ \\
\hline Age & 694 & 10.04196 & 4.15332 & 14.90212 \\
\hline Height & 4812 & 106.828 & 48 & 166.4 \\
\hline Weight & 4812 & & & \\
\hline Visithc & 4392 & 18.90039 & 2.8 & 52 \\
\hline Stage & 751 & 0.084016 & 0 & 8 \\
\hline CD4 & 1725 & 3.10253 & 2 & 4 \\
\hline CD4P & 1718 & 907.84 & 1 & 4000 \\
\hline Totlym & 1737 & 23.4851 & 0 & 82.9 \\
\hline Totlymp & 1737 & 3959.013 & 638 & 23387 \\
\hline Rooms & 553 & 48.89764 & 7.8 & 80.5 \\
\hline Expmeal & 553 & 3.886076 & 1 & 13 \\
\hline Expschool & 476 & 77153.14 & 0 & 884000 \\
\hline Expenergy & 553 & 133276.3 & 0 & 6500000 \\
\hline & & 90916.82 & 0 & 800003 \\
\hline
\end{tabular}

Source: Authors' estimates from CHAPAS data set

Variables: age = age in years; height = height in centimetres $(\mathrm{cm})$; weight $=$ weight in kilogrammes $(\mathrm{kg})$; visithc $=$ number of visits to the health centre; cd4 = cd4 count; $c d 4 p=c d 4$ percentage; Totlym = total lymphocyte; Totlymp = tota lymphocyte percentage; rooms = number of rooms in dwelling unit/house; Expmeal $=$ total monthly household expenditures on meals; Expschool $=$ monthly household expenditure on education; Expenergy = monthly household energy expenditures Table 2: Selected metrics of children.

\begin{tabular}{|c|c|c|c|c|c|}
\hline $\begin{array}{c}\text { Scale } \\
\text { domain }\end{array}$ & Observations & $\begin{array}{c}\text { Mean score } \\
\text { (Percentage) }\end{array}$ & $\begin{array}{c}\text { Standard } \\
\text { deviation }\end{array}$ & $\begin{array}{c}\text { Minimum } \\
\text { score }\end{array}$ & $\begin{array}{c}\text { Maximum } \\
\text { score }\end{array}$ \\
\hline $\begin{array}{c}\text { Physical } \\
\text { Functioning }\end{array}$ & 721 & 93.99 & 10.4 & 34 & 100 \\
\hline $\begin{array}{c}\text { Emotional } \\
\text { Functioning }\end{array}$ & 721 & 98.5 & 4.99 & 60 & 100 \\
\hline $\begin{array}{c}\text { Social } \\
\text { Functioning }\end{array}$ & 119 & 97.77 & 5.02 & 75 & 100 \\
\hline $\begin{array}{c}\text { School } \\
\text { Functioning }\end{array}$ & 658 & 87.78 & 12.53 & 30 & 100 \\
\hline $\begin{array}{c}\text { Psychosocial } \\
\text { Functioning }\end{array}$ & 101 & 94.50 & 6.41 & 67 & 100 \\
\hline $\begin{array}{c}\text { Total Scale } \\
\text { Scores }\end{array}$ & 101 & 95.12 & 6.24 & 58 & 100 \\
\hline
\end{tabular}

Source: Authors' calculations 
Citation: Chitah MB, Jonsson D, Seshamani V (2016) Investigating the Health Related Quality of Life of Zambian Children Living with HIVIAIDS on Antiretroviral Therapy. Health Econ Outcome Res Open Access 2: 120. doi: 10.4172/2471-268x/1000120

Page 4 of 5

differences in the extent of HRQoL by gender as shown in Table 6 below.

The results of the ordered probit regression model using time and HIV staging as categorical dependent variable are shown in Tables 7 and 8 respectively.

\section{Further Interpretation and Discussion of Results}

Table 7 above shows that the changes in HRQoL are positively related to time. The interpretation of this is associated with the low levels of CD4 at the time of initiation of ART. Based on the existing guidelines ART was initiated when CD4 count was in the region of 200250 or even lower in some cases. The average response shows that there was general improvement in the end points and outcome particularly in relation to CD4 count and mortality of the respondents. The results also show that there is a negative response associated with weight and total household expenditures-a rather counterintuitive outcome. However, these results are not significant.

In Table 8, the values cut $1(-2.07)$ and cut 2 (1.66) correspond to the HIV state showing that response of -2.07 corresponds to the staging of HIV that is the lowest and cut 2 value of 1.66 corresponds to staging above 1 . The variables totalexp and cd 4 count are not significant in the regression. The variables psychosocfn, weight, physfuntion and height show that individuals are likely to have lower staging of HIV/AIDS.

\begin{tabular}{|c|c|c|c|c|c|}
\hline HRQoL domain & Observations & Mean score & Standard deviation & \multicolumn{2}{|c|}{ Median score(Q1-Q3) } \\
\hline Health Perceptions (Total score) & 940 & 83.3 & 17.8 & 72.2 & 94.4 \\
\hline Physical Functioning & 940 & 100 & 29 & 75 & 100 \\
\hline $\begin{array}{l}\text { Emotional Functioning/Psychological } \\
\text { Functioning }\end{array}$ & 940 & 83.9 & 15.9 & 69.6 & 92.9 \\
\hline $\begin{array}{l}\text { Social Functioning } \\
\text { School Functioning }\end{array}$ & 940 & 80 & 23.1 & 60 & 100 \\
\hline HIV Symptoms & 940 & 95 & 10.4 & 88 & 98 \\
\hline
\end{tabular}

Source: Storm D S et al, (2005)

Table 4: Comparative results.

\begin{tabular}{|c|c|}
\hline Domain/Scale Item & Cronbach's $\boldsymbol{\alpha}$ score (\%) \\
\hline Physical functioning & 86 \\
\hline Emotional functioning & 70 \\
\hline Social functioning & 70 \\
\hline School functioning & 80 \\
\hline Total score & 80 \\
\hline
\end{tabular}

Source: Authors' computations

Table 5: Reliability: Cronbach's $\alpha$.

\begin{tabular}{|c|c|c|c|c|c|c|c|c|c|c|}
\hline \multirow[t]{2}{*}{ Domain/Scale } & \multicolumn{2}{|c|}{ Observations } & \multicolumn{2}{|c|}{ Mean } & \multicolumn{2}{|c|}{ Standard deviation } & \multicolumn{2}{|c|}{ Minimum } & \multicolumn{2}{|c|}{ Maximum } \\
\hline & Male & Female & Male & Female & Male & Female & Male & Female & Male & Female \\
\hline Physical functioning & 631 & 585 & 96 & 95 & 7.95 & 9.5 & 44 & 41 & 100 & 100 \\
\hline Emotional functioning & 631 & 585 & 98 & 98 & 5.66 & 6.7 & 65 & 60 & 100 & 100 \\
\hline Social functioning & 631 & 585 & 98 & 98 & 4.2 & 5.7 & 70 & 70 & 100 & 100 \\
\hline $\begin{array}{l}\text { Psycho-social } \\
\text { functioning }\end{array}$ & 573 & 520 & 94 & 95 & 6 & 7 & 62 & 67 & 100 & 100 \\
\hline Total score & 573 & 520 & 95 & 96 & 6.2 & 6.7 & 56 & 58 & 100 & 100 \\
\hline
\end{tabular}

Source: Authors' computations

Table 6: Comparative Male to Female Scores

\begin{tabular}{|c|c|c|c|c|}
\hline Nomweek & Coefficient & Standard Error & $z$ & $\mathrm{P}>|\mathrm{z}|$ \\
\hline Physfuntion & 0.030261 & 0.004398 & 6.88 & 0 \\
\hline Emotfuntion & 0.078796 & 0.007528 & 10.47 & 0 \\
\hline Socfuntion & 0.036126 & 0.007464 & 4.84 & 0 \\
\hline Psychosocfn & 0.006752 & 0.007113 & 0.95 & 0.342 \\
\hline Visithc & -0.20445 & 0.08362 & -2.45 & 0.014 \\
\hline Sex2 & 0.030451 & 0.049919 & 0.61 & 0.542 \\
\hline Totalexp & $-2.71 E-07$ & 4.91E-08 & -5.52 & 0 \\
\hline $\mathrm{cd} 4$ & 0.000108 & 6.36E-05 & 1.7 & 0.089 \\
\hline Height & -0.02406 & 0.004945 & -4.87 & 0 \\
\hline Weight & 0.05216 & 0.00971 & 5.37 & 0 \\
\hline
\end{tabular}

Notes: Nomweek = time in intervals of $\mathrm{HRQ}$ LL interviews and capture of haematological data, phyfuntion = physical functioning, emofuntion $=$ emotional functioning, Socfuntion = social functioning, psychosocfn = psychological and social functioning, schfuntion $=$ school (cognitive) functioning, visitch $=$ number of visits to the Health centre (clinical trial), sex $=$ male or female, totalexp $=$ total household expenditure,

$\mathrm{Cd} 4=\mathrm{CD} 4$ count, height $=$ height of respondent, weight $=$ weight of respondent,

Table 7: Ordered Probit Regression Model Using Time as a Categorical Dependent Variable. 
Citation: Chitah MB, Jonsson D, Seshamani V (2016) Investigating the Health Related Quality of Life of Zambian Children Living with HIVIAIDS on Antiretroviral Therapy. Health Econ Outcome Res Open Access 2: 120. doi: 10.4172/2471-268x/1000120

Page 5 of 5

\begin{tabular}{|c|c|c|c|c|}
\hline \multicolumn{5}{|l|}{ Variables } \\
\hline \multicolumn{5}{|l|}{ Dependent } \\
\hline Stage & Coefficient & Standard Error. & $\mathbf{z}$ & $P>|z|$ \\
\hline \multicolumn{5}{|l|}{ Independent } \\
\hline Physfuntion & -0.00444 & 0.005648 & -0.79 & 0.432 \\
\hline Emotfuntion & 0.033229 & 0.009217 & 3.61 & 0 \\
\hline Socfuntion & 0.007553 & 0.00953 & 0.79 & 0.428 \\
\hline Psychosocfn & -0.00775 & 0.01016 & -0.76 & 0.446 \\
\hline Visithc & 0.033794 & 0.116397 & 0.29 & 0.772 \\
\hline Sex2 & -0.06064 & 0.07275 & -0.83 & 0.405 \\
\hline Totalexp & $-5.29 \mathrm{E}-07$ & $6.81 \mathrm{E}-08$ & -7.77 & 0 \\
\hline CD4 & 0.000612 & 9.05E-05 & 6.77 & 0 \\
\hline Height & -0.01112 & 0.007298 & -1.52 & 0.128 \\
\hline Weight & -0.0483 & 0.014506 & -3.33 & 0.001 \\
\hline Cut1 & -2.07089 & 1.023028 & & \\
\hline Cut2 & 1.662964 & 1.020458 & & \\
\hline
\end{tabular}

Notes: phyfuntion = physical functioning, emofuntion = emotional functioning, Socfuntion = social functioning, psychosocfn = psychological and social functioning, Schfuntion $=$ school (cognitive) functioning, visitch = number of visits to the Health centre (clinical trial), sex2 = male or female, totalexp = total household expenditure, Cd4 $=C D 4$ count, height $=$ height of respondent, weight $=$ weight of respondent, Stage = HIV/AIDS stage at time of initiation of clinical trial

Table 8:Ordered Probit Regression Analysis with Staging of HIVIAIDS as categorical dependent variable.

\section{Conclusion}

HRQoL is an analytical method that has been scarcely applied with respect to not just children but adults as well. Reference to HRQoL studies within the sub-region has been limited to Zimbabwe and South Africa, and even in these cases the studies are limited to the adult population only. This is, therefore, the first study of its kind in Zambia.

Our study provides evidence of the contribution of ART to the desired outcomes through the improvements made in the quality of life. The various elements of the quality-of-life dimensions which affect cognitive abilities and physical and social-psychological functionality demonstrate improvements or added benefits for the beneficiaries of paediatric ARVs in comparison with a situation characterized by the absence of ARV interventions.

The above results provide a strong advocacy for the government not only to continue providing ARVs but to ensure universal access to the ARVs by children living with HIV/AIDS in Zambia.

\section{References}

1. Fairclough, Diane L (2002) Design and Analysis of Quality of Life Studies in Clinical Trials. Chapman and Hall/CRC Press Company, London.

2. Patrick D, Erickson P (1993) Health Policy, Quality of Life: Healthcare Evaluation and Resource Allocation. New York: Oxford University Press.

3. Ministry of Health (2005) Central Board of Health, Government of the Republic of Zambia. Zambia Antenatal Clinic Surveillance Report 1994-2004.

4. The World Health Organisation (2006) Antiretroviral Therapy of HIV Infection in Infants and Children: Towards Universal Access.

5. University of Zambia (2001) Medical Research Council, United Kingdom Clinical Protocol. A Randomised Placebo-controlled Trial of Trimethoprimsulfamethoxazole (TMP-SMX) as Prophylaxis against Opportunistic Infections in Children with Symptomatic HIV-1 Infection in Zambia (Children with HIV Antibiotic Prophylaxis Trial - CHAP Trial)

6. Storm D, Boland MG, Gortmaker SL, He Y, Skurnick J, et al. (2005) Protease Inhibitor Combination Therapy, Severity of Illness and Quality of Life among Children with Prenatally Acquired HIV-1 Infection. J Paediatr.

7. Varni JW, Seid M, Rode CA (1999) The PEDsQL: Measurement Model for the Paediatric Quality of Life Inventory. Med Care.

8. Varni JW, Limbers CW (2009) The Paediatric Quality of Life Inventory: Measuring Paediatric Health- Related Quality of Life from the Perspective of Children and Their Parents. Paediatric Clinics. 